\title{
Game Analysis, Validation, and Potential Application of EyeToy Play and Play 2 to Upper-Extremity Rehabilitation
}

\author{
Yu-ping Chen, ${ }^{1,2}$ Michelle Caldwell, ${ }^{1}$ Erica Dickerhoof, ${ }^{1}$ Anastasia Hall, ${ }^{1}$ Bryan Odakura, \\ Kimberly Morelli, ${ }^{1}$ and Hsin-Chen Fanchiang ${ }^{2}$ \\ ${ }^{1}$ Department of Physical Therapy, Georgia State University, P.O. Box 4019, Atlanta, GA 30302-4019, USA \\ ${ }^{2}$ Center for Pediatric Locomotion Sciences, Georgia State University, Atlanta, GA 30302-3975, USA \\ Correspondence should be addressed to Yu-ping Chen; ypchen@gsu.edu
}

Received 7 July 2014; Revised 4 December 2014; Accepted 8 December 2014; Published 25 December 2014

Academic Editor: Nicola Smania

Copyright (C) 2014 Yu-ping Chen et al. This is an open access article distributed under the Creative Commons Attribution License, which permits unrestricted use, distribution, and reproduction in any medium, provided the original work is properly cited.

Objective. To describe and analyze the potential use of games in the commercially available EyeToy Play and EyeToy Play 2 on required/targeted training skills and feedback provided for clinical application. Methods. A summary table including all games was created. Two movement experts naïve to the software validated required/targeted training skills and feedback for 10 randomly selected games. Ten healthy school-aged children played to further validate the required/targeted training skills. Results. All but two (muscular and cardiovascular endurance) had excellent agreement in required/targeted training skills, and there was 100\% agreement on feedback. Children's performance in required/targeted training skills (number of unilateral reaches and bilateral reaches, speed, muscular endurance, and cardiovascular endurance) significantly differed between games $(P<.05)$. Conclusion. EyeToy Play games could be used to train children's arm function. However, a careful evaluation of the games is needed since performance might not be consistent between players and therapists' interpretation.

\section{Introduction}

Recently, virtual reality (VR) has been explored as a training device for improving arm function in adults following stroke [1-5] and for children with cerebral palsy (CP) [6-8]. VR is a computer technology that creates an artificial but highly realistic graphical context and populates it with dynamic objects that allow users to interact with that context [9-12]. The process enables the creation of an exercise environment in which participants, either patients with stroke or children with $\mathrm{CP}$, can practice their arm movements intensively and receive visual and auditory feedback. There are several inexpensive, commercial VR gaming systems available now (e.g., PlayStation 2 with EyeToy Camera, Nintendo Wii systems, and Microsoft Kinect system), which increase the accessibility of utilizing VR systems for rehabilitation purposes like training arm function. Consequently, researchers have begun to investigate the effects of these commercially available games on the improvement of arm function in patients with stroke or children with CP $[1,2,5-8]$. The research has shown the potential for using the games to improve some aspects of arm function.

There are challenges in applying commercially available VR systems that were designed for recreation to do rehabilitation [13]. Deutsch et al. [13] noted that some interfaces might require adaptation (e.g., the Wii remote controller requires good hand control) and the level of difficulty of the games might not be suitable for some players, especially those with impaired arm function. Moreover, the skills required to play games might vary, which makes game selection difficult.

Deutsch et al. [13] created a detailed "game analysis table" to describe the games listed in Wii Sports and Wii Fit (Nintendo of America, Inc., Redmond, Washington), including game-related features (description, scoring, and progression), equipment used, length of game, feedback provided (knowledge of results or knowledge of performance), and impairments that can potentially benefit from the training (balance, coordination, endurance, strength, and upperextremity control). They validated their game analyses by rating the agreement of two experienced physical therapists 
who were naive to the games on feedback and impairment type. The researchers reported 100\% agreement between raters on ratings for impairment type and between $50 \%$ to $100 \%$ agreement on feedback provided.

In this study, we analyzed and validated games in the SONY PlayStation 2 EyeToy Play and EyeToy Play 2 (Sony Computer Entertainment American LLC, San Meteo, CA). EyeToy Play was selected because this system uses a USB camera as the method to capture players' motions, so that the players can see themselves as they are immersed in the virtual world. This software has been used in several studies to train arm movements in patients with stroke or children with CP and has been found effective [1, 2, 5-8]. Moreover, at $\$ 150$ for a new system, the selected unit is at the low end of the price range for commercially available video consoles. It thus has the greatest potential to be widely used in clinics and in children's homes. The purpose of this paper is to (1) provide a detailed summary table describing all the games in EyeToy Play and EyeToy Play 2 and (2) analyze and validate the specific games in EyeToy Play and EyeToy Play 2 for their potential to train for upper-extremity function in children. Finally, specific recommendations for upper-extremity function in children are also discussed.

\section{Materials and Methods}

This study included two phases: Phase I-creating a game summary table and Phase II-validating the items in the summary table using two movement experts (Phase II-1) and 10 typically developing children (Phase II-2).

\subsection{Phase I: Game Analysis and Game Summary Table} Creation. The first author (YC), who was experienced in using EyeToy Play and EyeToy Play 2 games to train children with cerebral palsy, created the items needed for inclusion in the game analysis table. These items were similar to Deutsch et al. [13] and included game features (e.g., goal of the game as listed by the software brochure, object to interact with), required/targeted training skills (e.g., unilateral reaching, bilateral reaching), feedback provided (e.g., knowledge of results), and special notes/comments (e.g., "game rules are unclear"). All items in the required/targeted training skills and feedback categories were defined based on motor learning and rehabilitation references (see Table 1 for definitions) [14-18]. Next, the first author and five physical therapy students played all the games as many times as needed to become conversant with them (range 5-8 times) and worked together to summarize each game in EyeToy Play and EyeToy Play 2 using the items listed earlier to describe the game, required/targeted training skills, feedback provided, and special comments. Table 2 provides an example of the "Beat Freak" game from EyeToy Play.

\subsection{Phase II: Validation Process of Game Summary Table}

2.2.1. Validation by Movement Experts. To determine agreement on the required/targeted training skills and feedback sections of the game summary table, a physical therapist rater $(\mathrm{KM})$ with more than 10 years of clinical experience in physical therapy and a movement scientist (HF) with a background in motor learning, biomechanics, and motion analysis evaluated 10 games randomly. The games were selected by putting all the relevant names from the game list into a bag and then randomly picking 10, similar to the method used by Deutsch et al. [13]. Six games from the EyeToy Play (Beat Freak, Kung Fu, Rocket Rumble, Slap Stream, Soccer Craze, and Wishi Washi) and four games from the EyeToy Play 2 (Bubble Pop, Goal Attack, Table Tennis, and Kung 2) were selected.

The two raters were naïve EyeToy players and seldom played video games. A short instruction session was conducted to go over the definitions of each item in the required/targeted training skills and feedback sections. The raters took turns playing and observing each other playing the game, and they were allowed as much time as they wanted for this phase. They then made ratings independently of each other after playing the game. Ratings were based on each rater's own playing experience as well as their observations of the other person. All items were rated either a "yes" or a "no." The raters also commented on whether to recommend the game as part of a therapeutic program for children who need to train their upper-extremity function. Percentage of agreement between the raters was then calculated. After the rating process was completed, a discussion session was held between the two raters and the first author in order to arrive at consensus on any inconsistent ratings. Changes were made in the game summary table if the consensus was different from the summary table ( 2 games on muscular endurance and 2 games on cardiovascular endurance were changed after discussion).

2.2.2. Validation by Testing Healthy Typically Developing Children. We further validated the required/targeted training skills section in our game summary table by having healthy, typically developing children play EyeToy Play and EyeToy Play 2 games. In this paper, we presented only unilateral reaching, bilateral reaching, speed, muscular endurance, and cardiovascular endurance as these items did not reach $100 \%$ agreement during the validation process by two movement experts (see Section 3 for details). We intentionally used children with typical development in this validation process because we needed to establish our reasonable expectations for children's regular performance in the commercial games before using a group of children with clinical diagnosis.

Participants. Ten children aged 6 to 12 years participated in this validation process (mean age: $8.20 \pm 1.69$ years old, 6 females 4 males). All participants were recruited from flyers or by word of mouth and were reported by their parents to be free of any neurological or orthopedic diseases and to have typical physical and cognitive development. Parents or legal guardians of the children signed an informed consent form prior to testing, and oral assents were obtained from the children.

Apparatus. The game console used was PlayStation 2 with EyeToy camera. The image was projected to a large screen 
TABLE 1: Definitions of required/targeted training skills and feedback provided.

\begin{tabular}{|c|c|c|}
\hline & $\begin{array}{l}\text { Conceptual definition used in Phases I and II-1 } \\
\text { validation by two movement experts }\end{array}$ & $\begin{array}{l}\text { Operational definition used in Phase II- } 2 \\
\text { validation by testing healthy children }\end{array}$ \\
\hline \multicolumn{3}{|l|}{ Required/targeted training skills } \\
\hline Unilateral reaching & $\begin{array}{l}\text { Movements of the upper extremities that use } 1 \text { hand or } \\
\text { arm. }\end{array}$ & $\begin{array}{l}\text { Number of upper-extremity movements } \\
\text { using } 1 \text { hand between } 30 \text { seconds after } \\
\text { play started and } 1 \text { minute and } 30 \text { seconds. }\end{array}$ \\
\hline Bilateral reaching & $\begin{array}{l}\text { Movements of the upper extremities that use } 2 \text { hands or } \\
\text { arms. Bilateral reaching can be symmetrical (both arms } \\
\text { perform the same joint motions) or alternative (e.g., } \\
\text { one arm is extending while the other is flexing). }\end{array}$ & $\begin{array}{l}\text { Number of upper-extremity movements } \\
\text { using both hands between } 30 \text { seconds } \\
\text { after play started and } 1 \text { minute and } 30 \\
\text { seconds. }\end{array}$ \\
\hline Speed & $\begin{array}{l}\text { The game requires the player to reach faster, since faster } \\
\text { is better. }\end{array}$ & Number of arm movements per minute \\
\hline Cognition & $\begin{array}{l}\text { This game requires some cognitive abilities. For } \\
\text { example, someone with intellectual disabilities may not } \\
\text { understand the game rules and may not be able to play } \\
\text { the game. }\end{array}$ & $\dagger$ \\
\hline Accuracy & The game requires some precision. & $\dagger$ \\
\hline Muscular endurance & $\begin{array}{l}\text { The ability of muscle to sustain forces repeatedly or to } \\
\text { generate forces over a period of time. Muscular } \\
\text { endurance refers to the body's ability to continue using } \\
\text { muscular strength and endure repeated contractions for } \\
\text { an extended period of time. Usually, if the game } \\
\text { requires the player to constantly repeat the same arm } \\
\text { movements over time, it requires muscular endurance. }\end{array}$ & $\begin{array}{l}\text { Total number of arm movements } \\
\text { performed in the } 3 \text {-minute interval }\end{array}$ \\
\hline Cardiovascular endurance & $\begin{array}{l}\text { The ability of the body to sustain prolonged rhythmical } \\
\text { exercise and perform work and participate in an activity } \\
\text { over time. Cardiovascular endurance is the power, } \\
\text { strength, or ability of the heart to supply enough } \\
\text { oxygen to muscles during a physical activity for a } \\
\text { prolonged period of time. It essentially indicates how } \\
\text { strong one's heart is and can potentially add years to } \\
\text { one's life. This can be measured by heart rate change. }\end{array}$ & $\begin{array}{l}\text { Four heart rate related indicators: } \\
\text { maximal heart rate change, maximal } \\
\text { heart rate, average heart rate, and } \\
\text { percentage of heart rate reserve }= \\
\text { (maximal heart rate during the } \\
\text { game-resting heart rate) } /[(208 \text {-age } * \\
0.7) \text { - resting heart rate] }\end{array}$ \\
\hline Eye-hand coordination & $\begin{array}{l}\text { The coordinated control of eye movement with hand } \\
\text { movement. The ability to guide the movements of the } \\
\text { hand with the eyes. }\end{array}$ & $\dagger$ \\
\hline Strength & $\begin{array}{l}\text { Muscle force exerted by a group of muscles to overcome } \\
\text { a resistance in a specific set of circumstances. }\end{array}$ & $\dagger$ \\
\hline \multicolumn{3}{|l|}{ Feedback provided } \\
\hline Knowledge of results & $\begin{array}{l}\text { Information about the outcome of the action Individual } \\
\text { action: information about the outcome of each action } \\
\text { (e.g., a banging sound after hitting an object). Whole } \\
\text { game: information about the outcome after playing the } \\
\text { whole game (e.g., the total score of the game, number of } \\
\text { opponents being hit) }\end{array}$ & $\dagger$ \\
\hline Knowledge of performance & $\begin{array}{l}\text { Information about the pattern of action, for example, } \\
\text { the player can see his/her movement while performing } \\
\text { the task. }\end{array}$ & $\dagger$ \\
\hline
\end{tabular}

$\dagger$ : reach 100\% agreement during the validation process by two movement experts in Phase II-1. It did not include Phase II-2 validation.

on the wall (size: $264 \mathrm{~cm} \times 220 \mathrm{~cm}$ ) to create better visibility for the children to interact with the virtual objects in the game. Nine games from the Validation Phase 1 were tested with these children, including Beat Freak, Bubble Pop, Goal Attack, Kung Fu, Rocket Rumble, Slap Stream, Soccer Craze, Table Tennis, and Wishi Washi. One game (Kung 2) from the previous list was not used because (1) this game was very similar to the original Kung $\mathrm{Fu}$, which might have left the children feeling bored and uninterested, and (2) the agreement on this game between the two movement experts was already excellent. The order of games to be played was randomized (using a table of random numbers) by a student who was not aware of the study purpose and naive to these games.

Participants' heart rate was measured using a Puma Children's Heart Rate monitoring system. A digital camera 
TABLE 2: Example of a complete game analysis table, using "Beat Freak" from EyeToy Play.

\begin{tabular}{|c|c|}
\hline & Beat freak \\
\hline \multicolumn{2}{|l|}{ (I) Game features } \\
\hline Goal of the game & Follow the CDs to hit the speakers to play the music. \\
\hline Context & $\begin{array}{l}\text { Reach to strike the speakers in the four corners of the screen just as the } \\
\text { CD reaches them. There are a few cartoon characters at the bottom of } \\
\text { the screen dancing and cheering for the player; however, they may } \\
\text { impede the player's view of their movements when hitting the speakers } \\
\text { at the two lower corners. }\end{array}$ \\
\hline Objects to interact with & CDs \\
\hline Object location & From the center to one of the 4 speakers located in the 4 corners. \\
\hline Appearance of the object & About 1.3-1.4 seconds \\
\hline Total duration of the game & 3 minutes \\
\hline Number of objects to interact with at once & $1-4$ \\
\hline Disturbing effects & None \\
\hline Avoiding objects/effects & None \\
\hline Speed of object appearance & $10 \mathrm{CDs} /$ the first 20 seconds \\
\hline Method to advance to different levels within the same game & None \\
\hline Method to end the game & Time is up or miss 3 CDs \\
\hline \multicolumn{2}{|l|}{ (II) Required skills } \\
\hline Unilateral reaching & Yes \\
\hline Bilateral reaching & Yes (for both symmetrical or asymmetrical) \\
\hline Speed & Yes \\
\hline Cognition & Yes \\
\hline Accuracy & Yes \\
\hline Muscular endurance & Yes \\
\hline Cardiovascular endurance & No \\
\hline Eye-hand coordination & Yes \\
\hline Strength & Yes \\
\hline \multicolumn{2}{|l|}{ (III) Feedback provided } \\
\hline Knowledge of results: individual action & Yes: auditory (when hitting the speaker) and visual (speaker lights up) \\
\hline Knowledge of results: whole game & Yes: score \\
\hline Knowledge of performance & Yes: the player can see his/her movement \\
\hline (IV) Special notes & Increase in speed and randomness throughout the game \\
\hline
\end{tabular}

(Apple, iPhone 5, at $30 \mathrm{~Hz}$ ) was placed about 15 degrees from the child's midline in front of the child to record the whole play sessions.

Procedures. All the testing took place in a university classroom. After assent and consent were obtained from children and their parent or legal guardians, participants placed the heart rate monitor strap around their chest and were asked to sit quietly for 5 minutes in order to measure their resting heart rate. Then the participants played nine EyeToy games in random order. One researcher was seated behind the participant to obtain the heart rate measurement from the heart rate monitor. For each game, the participant practiced the game for about 30 seconds before the recording started. The participant was instructed to play the game for 3 minutes, and heart rate was recorded at initiation and at 1-minute intervals. Rarely, if the game was accidentally interrupted before 3 minutes, a researcher reactivated the game immediately.
Participants took a 5-minute break after finishing each game and listened to the researcher explaining the rules for the next game. This break allowed participants' heart rate to return to its regular level. The parent was present throughout the testing period.

Data Reduction. Video data were exported to a computer and coded by the first author using Windows Movie Maker. The number of unilateral reaches, bilateral reaches, and total reaches was coded from the video using slow-motion and a frame-by-frame mode. Unilateral reaches were defined as the unilateral extension of one arm towards the location of a virtual object [19]. While one arm was moving, the other arm was held still, regardless of position (e.g., held at shoulder height or at the side of the body). Bilateral reaches were defined as simultaneous performance of both arm movements. To constitute a bilateral reach, the two arms did not need to move in the same direction, but both 
arms had to be moving. Our definitions were consistent with those of Deutsch et al. [13] and Corbetta and Thelen [20]. Unilateral and bilateral reaches were coded starting around 30 seconds after play started and coding continued for 1 minute. We did not code the complete trial or use the complete dataset to avoid the possible influence of fatigue on reaching frequency and also to avoid having a familiarization period, even though the participants had practiced before data collection. Since children could have a different number of reaches in the period of data collection, we converted the number of unilateral and bilateral reaches into percentages to normalize individual differences. The number of reaches per minute was used to represent speed. Reaches per minute were derived by combining the number of unilateral reaches and bilateral reaches within the coded minute. The higher number of reaches per minute is produced, the faster movement is required (i.e., faster speed).

We used the total number of reaches in the 3-minute interval as an indicator of muscular endurance since the more the reaches done by players, the greater the chance that the players would experience fatigue of the arm. If their muscular endurance was not good, they might do fewer reaches during the 3-minute session.

We also determined whether playing the games required cardiovascular endurance by measuring players' heart rate at initiation and at 1-minute intervals. Four different heartrate related variables were computed to represent the potential usefulness of each game for training cardiovascular endurance: maximal heart rate change, maximal heart rate, average heart rate, and percentage of heart rate reserve ([maximal heart rate during the game - resting heart rate]/[(208 age $* 0.7)$ - resting heart rate]) [21-23].

Analysis. For this observational study, we used descriptive statistics to report reaches and heart rate change in each game. The percentages of unilateral and bilateral reaches with each game, the number of reaches per minute, total number of reaches, and maximal heart rate change, maximal heart rate, average heart rate, and percentage of heart rate reserve with each game were compared between games using repeated analysis of variance (ANOVA), with games as the repeated factor. A preplanned paired $t$ test was used to determine where the differences were once the repeated ANOVA reached significance. All the analyses were conducted using SPSS 18.0.

\section{Results}

3.1. Game Summary Table. The completed game summary table for the EyeToy Play and EyeToy Play 2 games is in Table 3, which includes game related features, required/ targeted training skills, feedback provided, and recommendations. A summary of the number of games in EyeToy Play and EyeToy Play 2 that could potentially train the required/ targeted skills is given in Table 4 .

There are 12 games each in the EyeToy Play and EyeToy Play 2 software. Our analyses showed that 11 games in EyeToy Play and 10 games in EyeToy Play 2 enabled players to practice unilateral reaching; all the games in EyeToy
Play and 8 games in Play 2 enabled practice of bilateral reaching. Most of the games targeted speed, accuracy, eyehand coordination, and strength. Muscular endurance was targeted in 9 games each in EyeToy Play and EyeToy Play 2. Only 3 games in EyeToy Play and 1 game in EyeToy Play 2 targeted cardiovascular endurance, but this finding might be due to the difficulty in monitoring a player's heart rate without the proper apparatus (i.e., a heart rate monitor). All the games provided "Knowledge of Results" (KR) feedback, and all games but one provided "Knowledge of Performance" (KP) feedback.

Seven games from EyeToy Play and 9 games from EyeToy Play 2 are recommended to children who need to train upper-extremity function (see Table 3). Games were not recommended for children for the following reasons: four games (Plate Spinner, Mirror Game, UFO Juggler, and Monkey Bar) were not recommended because of difficult or confusing game rules, one game (Ghost Eliminator) was not recommended because of the scary scene, one game (Air Guitar) had no real reaching movements, and one game (Home Run) has a small and blurred display of the player on the screen. Among the recommended games, all but one (Goal Attack) can be used to train unilateral reaching, and all but two (Table Tennis and Secret Agent) can be used to train bilateral reaching. All of the recommended games target speed and strength and can provide KR and KP feedback. Four games in EyeToy Play and 8 games in EyeToy Play 2 require some cognition involvement; five games in EyeToy Play and all games in EyeToy Play 2 target accuracy during play.

\subsection{Validation of Game Summary Table-by Two Independent} Raters. Agreement between the two experts on items in the required/targeted training skills section ranged between $70 \%$ and $100 \%$; agreement on items in the feedback category was $100 \%$. The lowest agreement scores were on endurancerelated items (70\% and $80 \%$ for muscular and cardiovascular endurance, resp.). Agreement between raters on each game ranged between $83 \%$ and $100 \%$, with the lowest agreement on Soccer Craze $(83 \%)$. Percent agreement between the raters is shown in Table 5.

\subsection{Validation of Game Summary Table-by Testing 10 Children}

Unilateral and Bilateral Reaching. All these games produced both unilateral and bilateral reaches. However, there were statistically significant differences between games $(F(8,32)=$ 4.565, $P=.001)$. Children who played Slap Stream used mainly unilateral reaching, rather than bilateral reaching. Kung Fu, Rocket Rumble, Beat Freak, Table Tennis, Bubble Pop, and Soccer Craze also elicited more unilateral than bilateral reaching (see Table 6). Children used equal amount of unilateral and bilateral reaching when they played Wishi Washi, and they mainly used bilateral reaching when playing Goal Attack. These differences were statistically significant $(P<.05)$. 


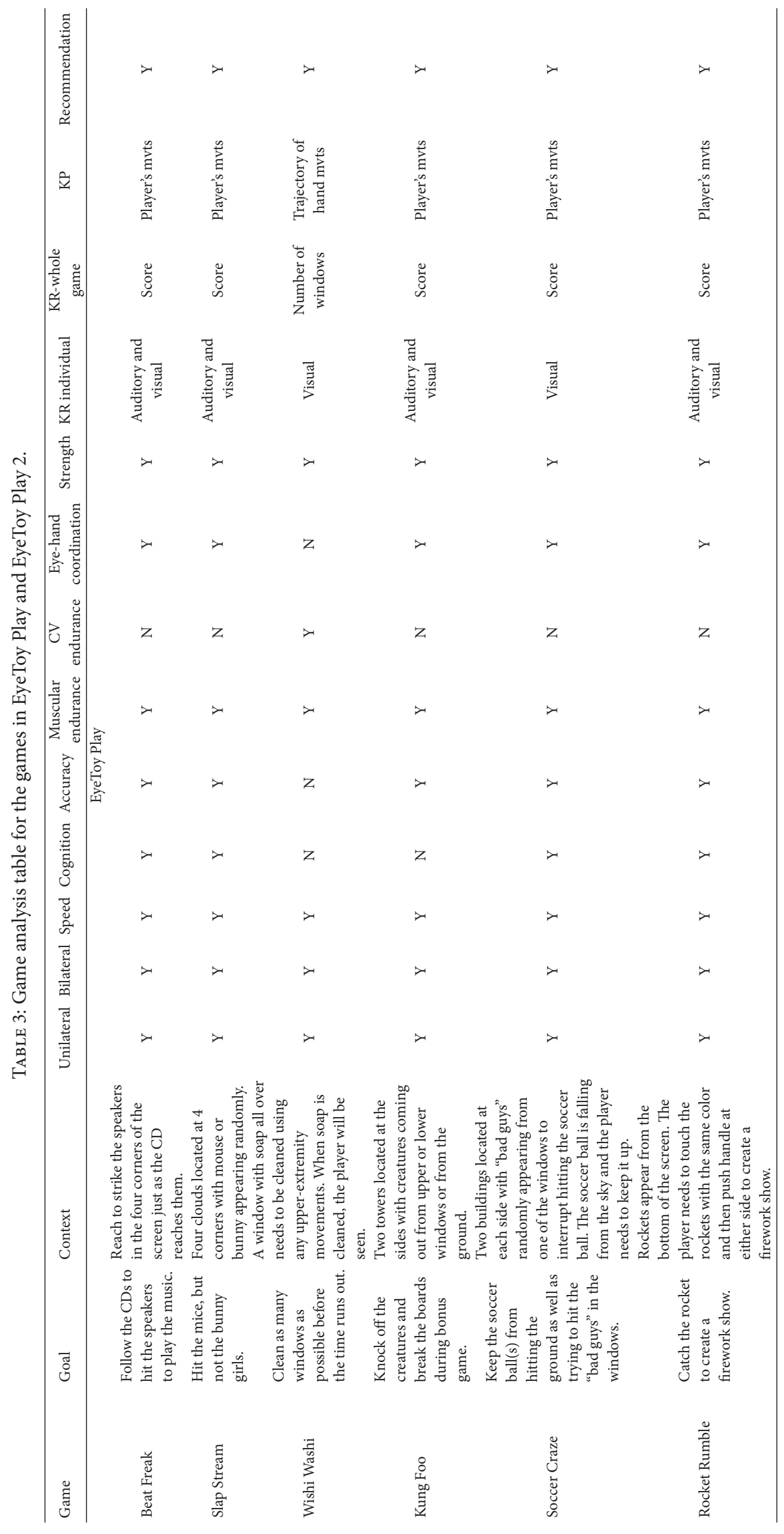




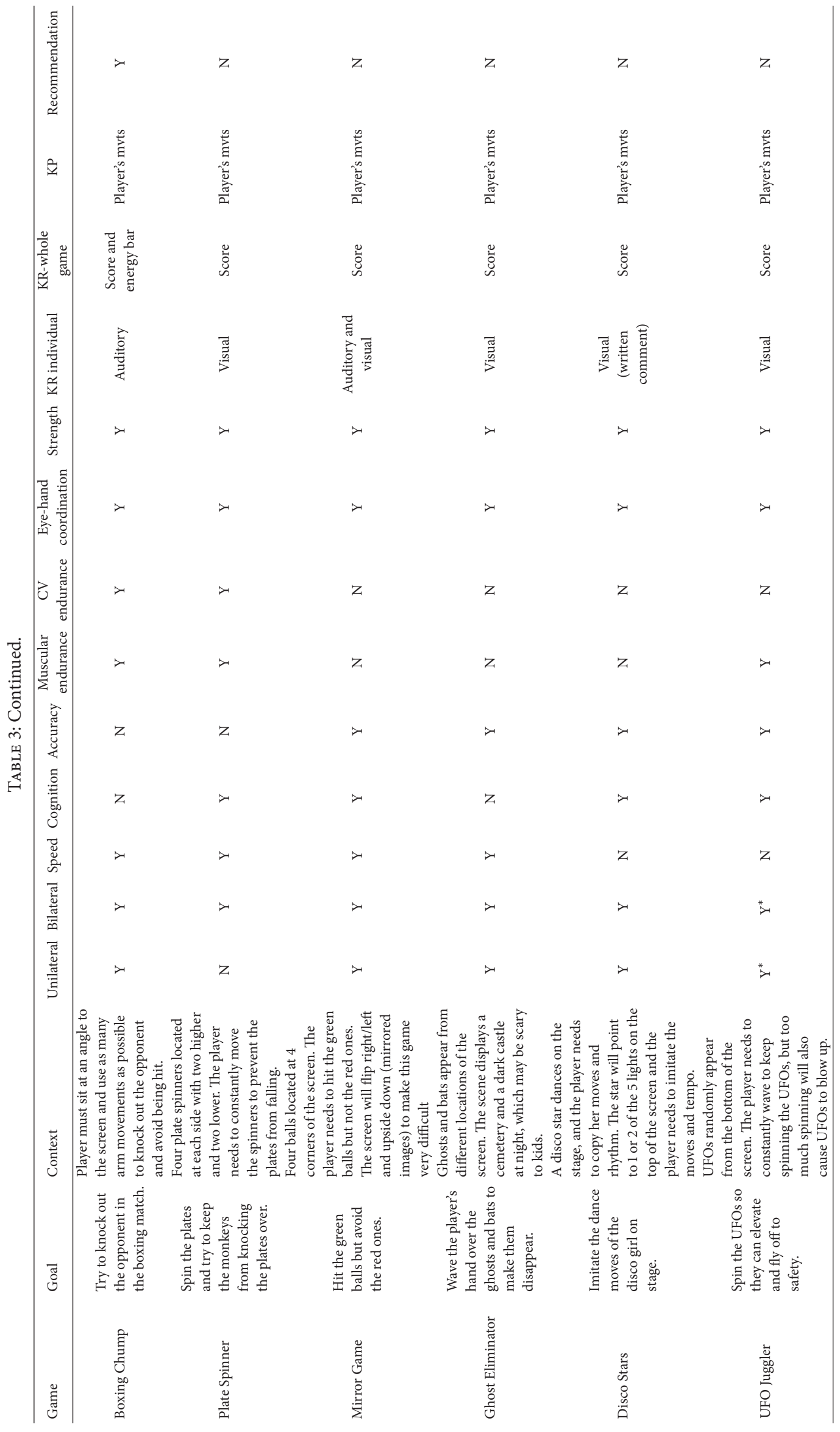




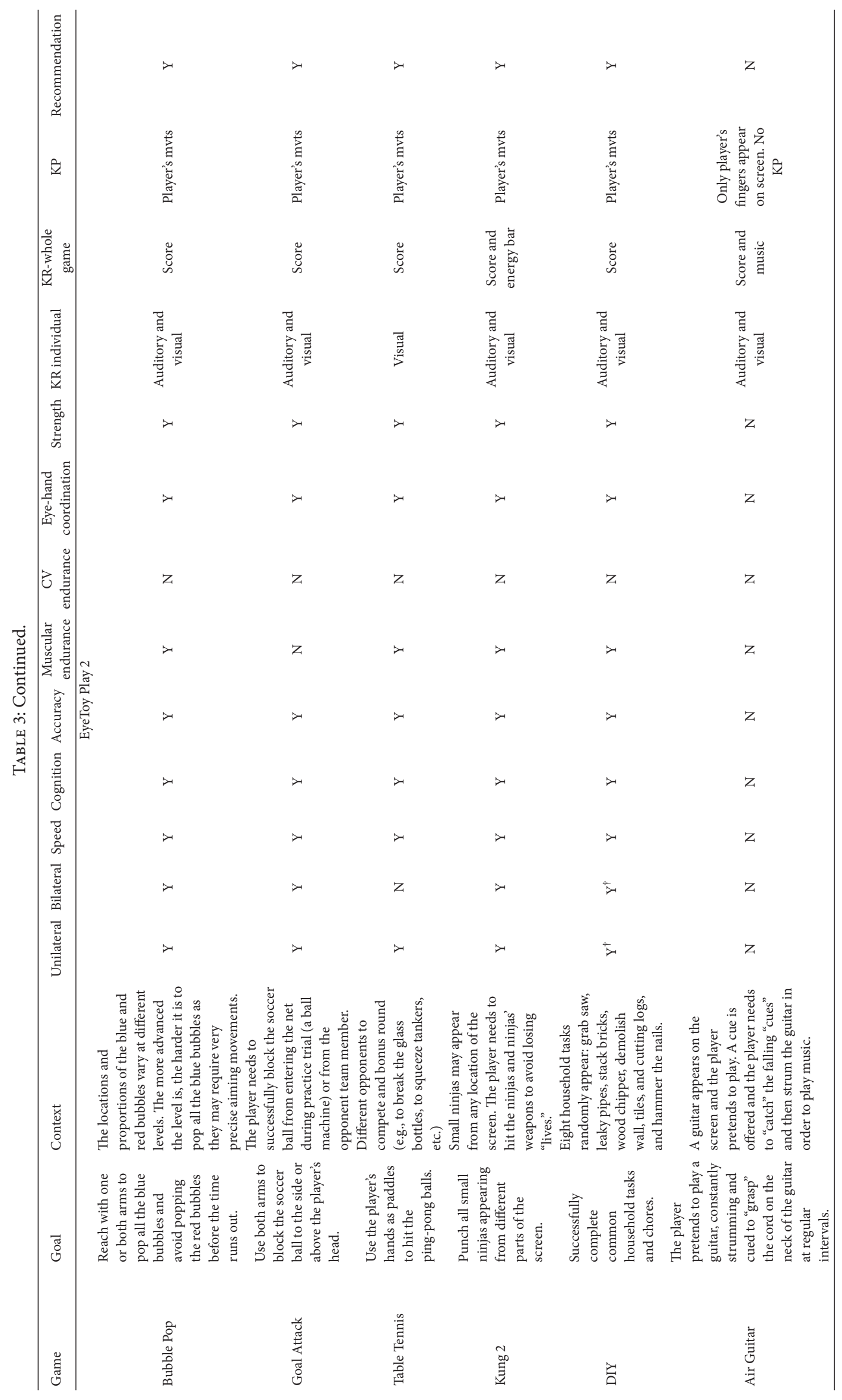




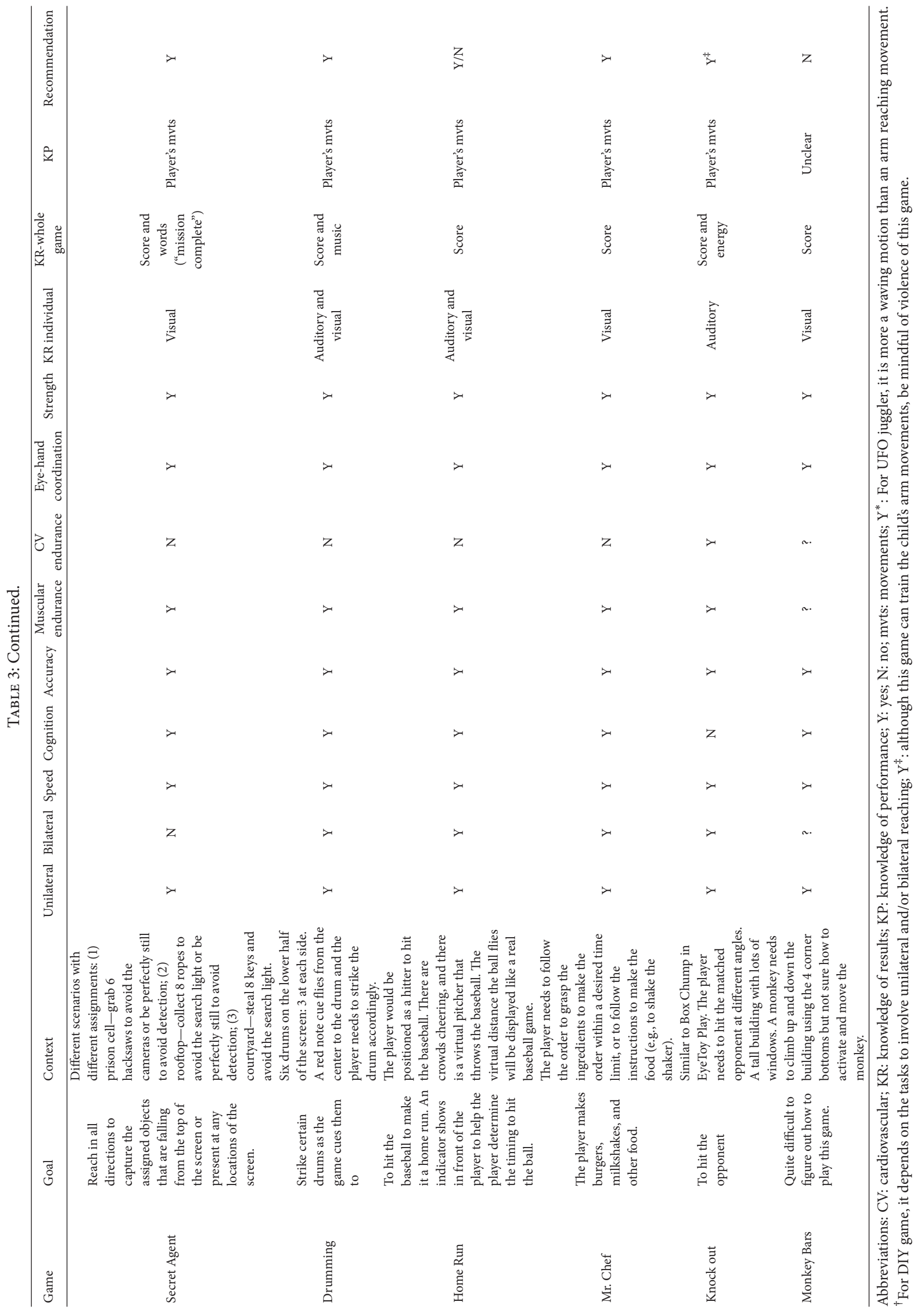


TABLE 4: Summary of number of games that could potentially train the required/targeted skills in EyeToy Play and EyeToy Play 2.

\begin{tabular}{lcc}
\hline & EyeToy Play & EyeToy Play 2 \\
\hline Unilateral reaching & $11(91.67 \%)$ & $10(83.33 \%)$ \\
Bilateral reaching & $12(100 \%)$ & $8(66.67 \%)$ \\
Speed & $10(83.33 \%)$ & $11(91.67 \%)$ \\
Cognition & $8(66.67 \%)$ & $10(83.33 \%)$ \\
Accuracy & $9(75.00 \%)$ & $11(91.67 \%)$ \\
$\begin{array}{l}\text { Muscular endurance } \\
\text { Cardiovascular }\end{array}$ & $9(75.00 \%)$ & $9(75.00 \%)$ \\
endurance & $3(25.00 \%)$ & $1(8.33 \%)$ \\
$\begin{array}{l}\text { Eye-hand } \\
\text { Coordination }\end{array}$ & $11(91.67 \%)$ & $11(91.67 \%)$ \\
$\begin{array}{l}\text { Knowledge of results: } \\
\text { individual action }\end{array}$ & $12(100.00 \%)$ & $11(91.67 \%)$ \\
$\begin{array}{l}\text { Knowledge of results: } \\
\text { Whole game }\end{array}$ & $12(100.00 \%)$ & $12(100.00 \%)$ \\
$\begin{array}{l}\text { Knowledge of } \\
\text { performance }\end{array}$ & $12(100.00 \%)$ & $12(100.00 \%)$ \\
Recommendation & $7(58.33 \%)$ & $9(75.00 \%)$ \\
\hline
\end{tabular}

TABle 5: Percent agreement between two independent raters by game and by item.

\begin{tabular}{lclc}
\hline By game & Agreement & By item & Agreement \\
\hline Beat Freak & $100.00 \%$ & Unilateral reaching & $100.00 \%$ \\
Kung Fu & $92.31 \%$ & Bilateral reaching & $90.00 \%$ \\
Rocket Rumble & $100.00 \%$ & Speed & $90.00 \%$ \\
Slap Stream & $100.00 \%$ & Cognition & $100.00 \%$ \\
Soccer Craze & $84.62 \%$ & Accuracy & $100.00 \%$ \\
Wishi Washi & $92.31 \%$ & Muscular endurance & $70.00 \%$ \\
Bubble Pop & $92.31 \%$ & Cardiovascular & endurance \\
Goal Attack & $92.31 \%$ & Eye-hand & $80.00 \%$ \\
Kung 2 & $100.00 \%$ & Strength & $100.00 \%$ \\
Table Tennis & $92.31 \%$ & Feedback provided & $100.00 \%$ \\
& & Knowledge of results: & $100.00 \%$ \\
& & Individual action & \\
& & $\begin{array}{l}\text { Knowledge of results: } \\
\text { Whole game }\end{array}$ & $100.00 \%$ \\
& & Knowledge of & $100.00 \%$ \\
& & performance & Recommendation \\
& & & $90.00 \%$ \\
\hline
\end{tabular}

Speed. Number of arm movements ranged from 15.17 to 79.10 per minutes and differed statistically different between games $(F(8,32)=3.416, P=.006)$. Children did more movements per minute when playing WishiWashi and Rocket Rumble and fewer when playing Goal Attack.
Muscular Endurance. Muscular endurance was operationalized as the total number of reaching movements in the 3minute playing interval. Wishi Washi produced the greatest number of reaches, followed by Bubble Pop, Rocket Rumble, Kung Fu, Soccer Craze, and Beat Freak. Goal Attack produced the smallest number of reaches. Table Tennis and Slap Stream also tended to produce fewer reaches than other games. The difference between games for number of reaches was statistically significant $(F(8,64)=3.55, P=.002)$.

Cardiovascular Endurance. Cardiovascular endurance was operationalized using maximal heart rate change, maximal heart rate, average heart rate, and percentage of heart rate reserve as indicators. All of these variables indicated similar trends: Soccer Craze, Kung Fu, and Wishi Washi elicited the largest maximal heart rate change, maximal heart rate, average heart rate, and percentage of heart rate reserve, followed by Beat Freak, Rocket Rumble, and Table Tennis. Slap Stream, Goal Attack, and Bubble Pop had the smallest heart rate change, maximal heart rate, average heart rate, and percentage of heart rate reserve.

\section{Discussion}

The primary goals of this study were to provide summary of the games in EyeToy Play and EyeToy Play 2 and to validate the game table for future use by clinicians. Seven games from the EyeToy Play and 9 games from the EyeToy Play2 are recommended for children who need to train upperextremity function. Almost all of the 16 games can be used to train unilateral and bilateral reaching movements and provide proper feedback. Some games, however, require more cognitive involvement than others, and some games can be specifically used to train for accuracy or for speed of reaching movements. The detailed game analysis table can also help clinicians select the games they recommend to their clients for use in training reaching movements.

Agreement by movement experts on the required/targeted training skills rating ranged from $70 \%$ to $100 \%$. As expected, the two items with the lowest agreement were related to endurance (muscular endurance and cardiovascular endurance). Muscular endurance was defined as "the ability of muscle to sustain forces repeatedly or to generate forces over a period of time," but even though we suggested the use of total arm movements during the 3-minute period, this was hard to operationalize because the strategies used to play the games varied slightly between players. For example, when playing the game of Soccer Craze, the two movement experts (i.e., the two raters) in our study used different strategies to complete the game: Rater 1 used quick and short arm movements to keep the soccer ball in the air, while Rater 2 used a different strategy, moving the arm slowly but more precisely. Both strategies worked since both raters were able to play the game for at least 3 minutes. Cardiovascular endurance was also difficult to rate since it is difficult to be measured directly. The rest of the required/targeted training skills were highly consistent between the two raters, showing excellent validity of the game analysis table. 
TABLE 6: Quantitative validation of the game analysis table using 10 children with typical development.

\begin{tabular}{|c|c|c|c|c|c|c|c|c|}
\hline Game & $\begin{array}{l}\text { Unilateral } \\
\text { reaching* }\end{array}$ & $\begin{array}{l}\text { Bilateral } \\
\text { reaching* }\end{array}$ & $\begin{array}{c}\text { Speed }^{*} \\
\text { (\# arm } \\
\text { mvts/min) }\end{array}$ & $\begin{array}{c}\text { Number of } \\
\text { total arm } \\
\text { mvts }^{*}\end{array}$ & $\begin{array}{c}\text { Maximal } \\
\text { heart rate } \\
\text { change }\end{array}$ & $\begin{array}{c}\text { Maximal } \\
\text { heart rate }\end{array}$ & $\begin{array}{l}\text { Average heart } \\
\text { rate }^{*}\end{array}$ & $\begin{array}{c}\text { Percentage of } \\
\text { heart rate } \\
\text { reserve }\end{array}$ \\
\hline Beat Freak & $\begin{array}{c}75.04 \% \\
(12.42 \%)\end{array}$ & $\begin{array}{c}24.96 \% \\
(12.42 \%)\end{array}$ & $\begin{array}{l}51.00 \\
(11.32)\end{array}$ & $\begin{array}{l}187.88 \\
(97.96)\end{array}$ & $\begin{array}{c}23.60 \\
(18.33)\end{array}$ & $\begin{array}{l}132.70 \\
(13.14)\end{array}$ & $\begin{array}{l}122.40 \\
(12.69)\end{array}$ & $\begin{array}{c}36.10 \% \\
(14.51 \%)\end{array}$ \\
\hline Kung Fu & $\begin{array}{c}84.76 \% \\
(12.75 \%)\end{array}$ & $\begin{array}{c}15.24 \% \\
(12.75 \%)\end{array}$ & $\begin{array}{c}49.22 \\
(13.84)\end{array}$ & $\begin{array}{l}166.89 \\
(82.44)\end{array}$ & $\begin{array}{c}35.10 \\
(17.52)\end{array}$ & $\begin{array}{l}147.20 \\
(17.62)\end{array}$ & $\begin{array}{l}130.13 \\
(16.21)\end{array}$ & $\begin{array}{c}44.63 \% \\
(17.87 \%)\end{array}$ \\
\hline Rocket Rumble & $\begin{array}{c}81.42 \% \\
(23.46 \%)\end{array}$ & $\begin{array}{c}18.58 \% \\
(23.46 \%)\end{array}$ & $\begin{array}{c}62.78 \\
(36.21)\end{array}$ & $\begin{array}{c}253.33 \\
(234.52)\end{array}$ & $\begin{array}{c}23.00 \\
(18.97)\end{array}$ & $\begin{array}{l}140.90 \\
(25.43)\end{array}$ & $\begin{array}{l}128.55 \\
(16.75)\end{array}$ & $\begin{array}{c}41.24 \% \\
(19.30 \%)\end{array}$ \\
\hline Slap Stream & $\begin{array}{l}98.78 \% \\
(2.74 \%)\end{array}$ & $\begin{array}{c}1.22 \% \\
(2.74 \%)\end{array}$ & $\begin{array}{c}41.11 \\
(13.73)\end{array}$ & $\begin{array}{l}125.44 \\
(54.02)\end{array}$ & $\begin{array}{l}16.30 \\
(9.55)\end{array}$ & $\begin{array}{l}128.60 \\
(10.52)\end{array}$ & $\begin{array}{l}120.47 \\
(13.58)\end{array}$ & $\begin{array}{c}33.18 \% \\
(10.72 \%)\end{array}$ \\
\hline Soccer Craze & $\begin{array}{c}65.80 \% \\
(36.88 \%)\end{array}$ & $\begin{array}{c}34.20 \% \\
(36.88 \%)\end{array}$ & $\begin{array}{c}35.90 \\
(13.63)\end{array}$ & $\begin{array}{c}159.89 \\
(64.76)\end{array}$ & $\begin{array}{l}38.60 \\
(21.14)\end{array}$ & $\begin{array}{l}154.70 \\
(24.82)\end{array}$ & $\begin{array}{l}137.78 \\
(17.89)\end{array}$ & $\begin{array}{c}53.18 \% \\
(20.47 \%)\end{array}$ \\
\hline Wishi Washi & $\begin{array}{c}54.67 \% \\
(42.15 \%)\end{array}$ & $\begin{array}{c}45.33 \% \\
(42.15 \%)\end{array}$ & $\begin{array}{c}79.10 \\
(32.78)\end{array}$ & $\begin{array}{c}456.78 \\
(415.93)\end{array}$ & $\begin{array}{c}33.50 \\
(17.83)\end{array}$ & $\begin{array}{l}145.60 \\
(17.65)\end{array}$ & $\begin{array}{l}131.43 \\
(17.23)\end{array}$ & $\begin{array}{c}46.74 \% \\
(18.40 \%)\end{array}$ \\
\hline Bubble Pop & $\begin{array}{c}75.52 \% \\
(12.56 \%)\end{array}$ & $\begin{array}{c}24.48 \% \\
(12.56 \%)\end{array}$ & $\begin{array}{c}40.14 \\
(21.42)\end{array}$ & $\begin{array}{c}335.22 \\
(421.66)\end{array}$ & $\begin{array}{l}19.10 \\
(7.52)\end{array}$ & $\begin{array}{l}131.60 \\
(15.79)\end{array}$ & $\begin{array}{l}121.30 \\
(14.44)\end{array}$ & $\begin{array}{c}33.84 \% \\
(11.46 \%)\end{array}$ \\
\hline Goal Attack & $\begin{array}{c}21.00 \% \\
(22.26 \%)\end{array}$ & $\begin{array}{c}79.00 \% \\
(22.26 \%)\end{array}$ & $\begin{array}{c}15.17 \\
(5.85)\end{array}$ & $\begin{array}{c}67.33 \\
(38.68)\end{array}$ & $\begin{array}{l}16.00 \\
(9.80)\end{array}$ & $\begin{array}{l}129.20 \\
(12.02)\end{array}$ & $\begin{array}{l}121.15 \\
(12.52)\end{array}$ & $\begin{array}{c}33.30 \% \\
(11.46 \%)\end{array}$ \\
\hline Table Tennis & $\begin{array}{c}76.59 \% \\
(34.19 \%)\end{array}$ & $\begin{array}{c}23.41 \% \\
(34.19 \%)\end{array}$ & $\begin{array}{c}33.56 \\
(15.37)\end{array}$ & $\begin{array}{l}125.56 \\
(68.38)\end{array}$ & $\begin{array}{c}25.20 \\
(16.61)\end{array}$ & $\begin{array}{l}133.40 \\
(16.22)\end{array}$ & $\begin{array}{l}121.65 \\
(12.58)\end{array}$ & $\begin{array}{c}35.17 \% \\
(16.82 \%)\end{array}$ \\
\hline
\end{tabular}

${ }^{*} P<.05$ : a statistical significance was found between games; the value in parentheses is the standard deviation; mvts: movements.

Unlike the rating scheme for feedback (KR or KP) developed by Deutsch et al. [13], the two raters agreed 100\% on whether the individual games they rated could provide KR and/or KP. One possible explanation would be that we used a dichotomous variable (yes/no) to rate feedback, rather than a Likert scale, which narrowed the range of responses and thus increased the likelihood of agreement. Another possible explanation is that the EyeToy games had a USB camera to capture the player's movements on screen, providing oneto-one corresponding movements, which made the rating of feedback for KP very easy since the player could see his/her movement on the screen.

Our study further validated those games which did not have a perfect agreement by 10 healthy, typically developing children playing the games. We videotaped the children playing the games in a random order and used a heart rate monitor to measure their heart rates. We coded their reaches and counted their total reaching movements during the 3minute game. Interestingly, although all 9 games elicited unilateral and bilateral reaching, some games produced more unilateral reaches than others (e.g., Slap Stream) and some games elicited more bilateral reaches than others (e.g., Goal Attack). The number of arm movements per minute was used to represent the speed in the required/targeted training skills. Wishi Washi and Rocket Rumble were the two games required fast speed, whereas Goal Attack did not. We used the count of total arm movements during the entire 3-minute session to represent muscular endurance and four heart rate related measures to represent cardiovascular endurance. Wishi Washi, Bubble Pop, and Rocket Rumble produced more arm movements than the other games, indicating that these games might be used for training more muscular endurance if players can finish the game. Interestingly, all 4 heart rate related measures indicated similar trends among the 9 games: Soccer Craze, Kung Fu, and Wishi Washi increased heart rate more than Slap Stream, Goal Attack, and Bubble Pop.

Generally, the ratings between the movement experts and children's performance were quite consistent in unilateral reaching, bilateral reaching, speed, and muscular endurance. Only one game (Goal Attack) differed between the experts and children's performance in speed, which was operationally defined as number of arm movements per minute. The experts rated all games as requiring/targeting speed; however, the children's performance showed that Goal Attack generated just 15 arm movements per minute (in other words, it was relatively slow). Using the standard reported by Lythgo et al. [24, 25], a typical school-aged child doing a daily activity like walking can generate about 30 arm movements per minute, yet Goal Attack produced a slower frequency of arm movements, which was different from the experts' rating. Unilateral reaching, bilateral reaching, and muscular endurance were consistent between the experts' ratings and the children's performance.

Cardiovascular endurance was the item showing the most inconsistency between the experts' rating and children's performance. In the expert's rating, only Wishi Washi required/targeted cardiovascular endurance. However, from the children's performance, all games on average reached at least $33 \%$ of their heart rate reserve. It is worth noting that 4 games (Kung Fu, Rocket Rumble, Soccer Craze, and Wishi Washi) exceeded $40 \%$ of heart rate reserve, which is the recommendation of the American College of Sport Medicine for aerobic training [18]. This suggests that these games would have the potential to train children's cardiovascular endurance. This inconsistency when rating cardiovascular 
endurance suggests that therapists might be based on their own experience and expertise to make the exercise prescription to children which may not be accurate because children's movement strategies may differ from adults. If this is true, then therapists would need to observe the children in action in order to make correct recommendations.

There are some limitations in this study. The sample size used in this study was only 10 , though the children performed quite consistently among themselves. Future studies should include a larger sample and should also include children with need to train arm function (e.g., cerebral palsy) since their responses may not be the same as those of children with typical development. In addition, the heart rate monitor used in the current study could not store heart rate data; therefore, the actual amount by which heart rate exceeded the training zone ( $40 \%$ of heart rate reserve) could not be calculated. Future studies should include a more sensitive heart rate monitor to examine the effect of VR games on cardiovascular endurance. Also, our definition of "speed" was based on number of arm movements per minute which might not be the best definition, as we did not directly measure the speed of the arm movements. A sensitive motion analysis system and eye tracker may be needed to examine the speed and accuracy of participants' movements and even eye-hand coordination.

\section{Conclusion}

Our study provides a detailed summary table for the games in Sony PlayStation 2 EyeToy Play and EyeToy Play2. Moreover, although these games are not designed specifically for children who need to train their arm function, our research shows that some of the games studied could be useful therapeutic tools to improve their reaching abilities. For example, if the goal is to target unilateral reaching, Slap Stream might be a good game to train for that. If the goal is to train muscular endurance, Wishi Washi, Bubble Pop, and Rocket Rumble might be the best choices. If cardiovascular endurance is the training goal, Soccer Craze, Kung Fu, and Wishi Washi might be the best games. The advancement of new technology has promise to move treatment forward at a low cost; however, a careful evaluation of the games is needed since performance might not be consistent between players and therapists' interpretation.

\section{Conflict of Interests}

The authors declare that there is no conflict of interests regarding the publication of this paper.

\section{Acknowledgments}

The authors acknowledge and thank Dr. Shih-Yu Lee for her comments on an earlier draft of this paper. Danielle August, PT, DPT, Sarah Harper, PT, DPT, Krista Penninger, PT, DPT, Lauren Perry, PT, DPT, and LaToyia Williams, PT, DPT, contributed to earlier versions of Table 3 . This study was supported in part by a GSU internal grant awarded to the first author. The authors alone are responsible for the content and writing of this paper.

\section{References}

[1] S. Flynn, P. Palma, and A. Bender, "Feasibility of using the Sony PlayStation 2 gaming platform for an individual poststroke: a case report," Journal of Neurologic Physical Therapy, vol. 31, no. 4, pp. 180-189, 2007.

[2] A. Neil, S. Ens, R. Pelletier, T. Jarus, and D. Rand, "Sony PlayStation EyeToy elicits higher levels of movement than the Nintendo Wii: implications for stroke rehabilitation," European Journal of Physical and Rehabilitation Medicine, vol. 49, no. 1, pp. 13-21, 2013.

[3] D. M. Peters, A. K. McPherson, B. Fletcher, B. A. McClenaghan, and S. L. Fritz, "Counting repetitions: an observational study of video game play in people with chronic poststroke hemiparesis," The Journal of Neurologic Physical Therapy, vol. 37, no. 3, pp. 105111, 2013.

[4] D. Rand, R. Kizony, and P. T. L. Weiss, “The sony playstation II eye toy: low-cost virtual reality for use in rehabilitation," Journal of Neurologic Physical Therapy, vol. 32, no. 4, pp. 155-163, 2008.

[5] G. Yavuzer, A. Senel, M. B. Atay, and H. J. Stam, “"Playstation eyetoy games' improve upper extremity-related motor functioning in subacute stroke: a randomized controlled clinical trial," European Journal of Physical and Rehabilitation Medicine, vol. 44, no. 3, pp. 237-244, 2008.

[6] Y.-P. Chen, L.-J. Kang, T.-Y. Chuang et al., "Use of virtual reality to improve upper-extremity control in children with cerebral palsy: a single-subject design," Physical Therapy, vol. 87, no. 11, pp. 1441-1457, 2007.

[7] Y.-P. Chen, S.-Y. Lee, and A. M. Howard, "Effect of virtual reality on upper extremity function in children with cerebral palsy: a meta-analysis," Pediatric Physical Therapy, vol. 26, no. 3, pp. 289-300, 2014.

[8] M. J. A. Jannink, G. J. van der Wilden, D. W. Navis, G. Visser, J. Gussinklo, and M. Ijzerman, "A low-cost video game applied for training of upper extremity function in children with cerebral palsy: a pilot study," Cyberpsychology \& Behavior, vol. 11, no. 1, pp. 27-32, 2008.

[9] T. D. Parsons, A. A. Rizzo, S. Rogers, and P. York, "Virtual reality in paediatric rehabilitation: a review," Developmental Neurorehabilitation, vol. 12, no. 4, pp. 224-238, 2009.

[10] L. Snider, A. Majnemer, and V. Darsaklis, "Virtual reality as a therapeutic modality for children with cerebral palsy," Developmental Neurorehabilitation, vol. 13, no. 2, pp. 120-128, 2010.

[11] P. L. Weiss, D. Rand, N. Katz, and R. Kizony, "Video capture virtual reality as a flexible and effective rehabilitation tool," Journal of NeuroEngineering and Rehabilitation, vol. 1, article 12, 2004.

[12] P. N. Wilson, N. Foreman, and D. Stanton, "Virtual reality, disability and rehabilitation," Disability and Rehabilitation, vol. 19, no. 6, pp. 213-220, 1997.

[13] J. E. Deutsch, A. Brettler, C. Smith et al., "Nintendo Wii sports and Wii fit game analysis, validation, and application to stroke rehabilitation," Topics in Stroke Rehabilitation, vol. 18, no. 6, pp. 701-719, 2011.

[14] R. A. Magill, Motor Learning and Control: Concepts and Applications, McGraw-Hill Companies, New York, NY, USA, 9th edition, 2010. 
[15] A. Shumway-Cook and M. Woollacott, Motor Control: Translating Research into Clinical Practice, Lippincott Williams \& Wilkins, Baltimore, Md, USA, 4th edition, 2011.

[16] R. A. Schmidt and T. D. Lee, Motor Control and Learning: A Behavioral Emphasis, Human Kinetics, Champaign, Ill, USA, 5th edition, 2011.

[17] APTA, Ed., Guide to Physical Therapist Practice, American Physical Therapy Association, Alexandria, Va, USA, 2nd edition, 2003.

[18] ACSM, Ed., ACSM's Guidelines for Exercise Testing and Prescription, Lippincott Williams \& Wilkins, Philadelplhia, Pa, USA, 9th edition, 2013.

[19] L. Fetters and J. Todd, "Quantitative assessment of infant reaching movements," Journal of Motor Behavior, vol. 19, no. 2, pp. 147-166, 1987.

[20] D. Corbetta and E. Thelen, "The developmental origins of bimanual coordination: a dynamic perspective," Journal of Experimental Psychology: Human Perception and Performance, vol. 22, no. 2, pp. 502-522, 1996.

[21] F. A. Machado and B. S. Denadai, "Validity of maximum heart rate prediction equations for children and adolescents," Arquivos Brasileiros de Cardiologia, vol. 97, no. 2, pp. 136-140, 2011.

[22] A. D. Mahon, A. D. Marjerrison, J. D. Lee, M. E. Woodruff, and L. E. Hanna, "Evaluating the prediction of maximal heart rate in children and adolescents," Research Quarterly for Exercise and Sport, vol. 81, no. 4, pp. 466-471, 2010.

[23] M. Robert, L. Ballaz, R. Hart, and M. Lemay, "Exercise intensity levels in children with cerebral palsy while playing with an active video game console," Physical Therapy, vol. 93, no. 8, pp. 1084-1091, 2013.

[24] N. Lythgo, C. Wilson, and M. Galea, "Basic gait and symmetry measures for primary school-aged children and young adults whilst walking barefoot and with shoes," Gait \& Posture, vol. 30, no. 4, pp. 502-506, 2009.

[25] N. Lythgo, C. Wilson, and M. Galea, "Basic gait and symmetry measures for primary school-aged children and young adults. II: walking at slow, free and fast speed," Gait \& Posture, vol. 33, no. 1, pp. 29-35, 2011. 


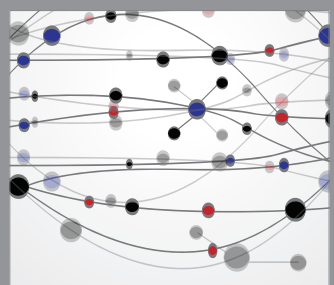

The Scientific World Journal
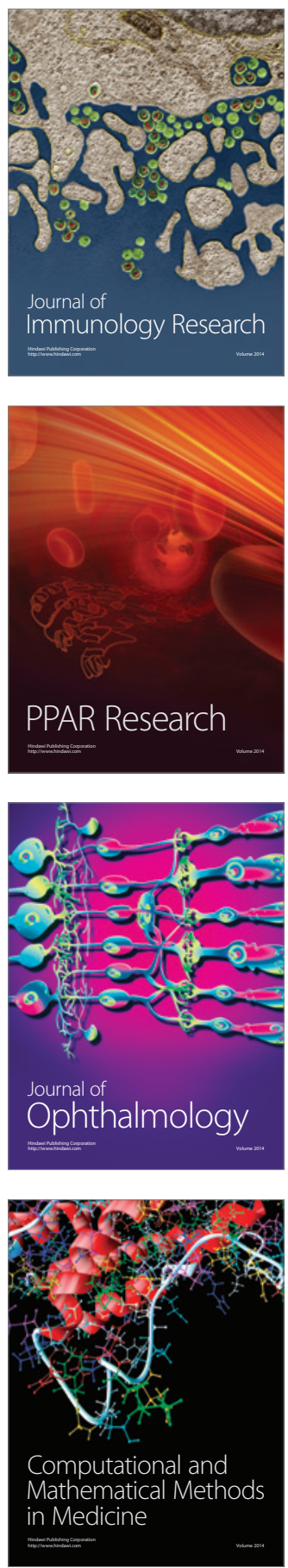

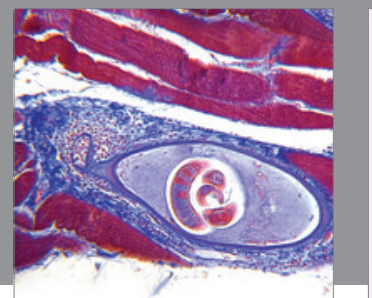

Gastroenterology

Research and Practice
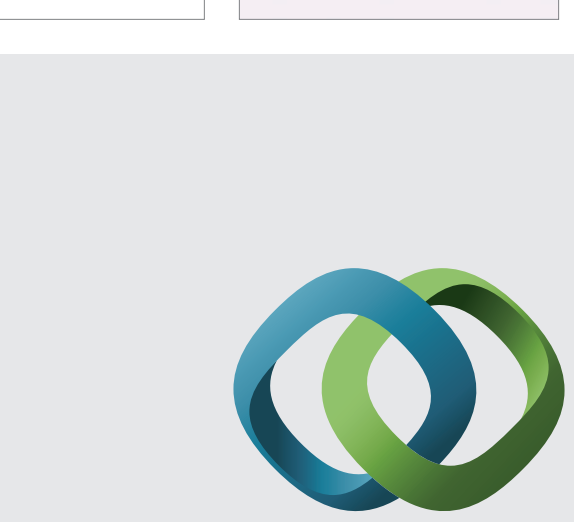

\section{Hindawi}

Submit your manuscripts at

http://www.hindawi.com
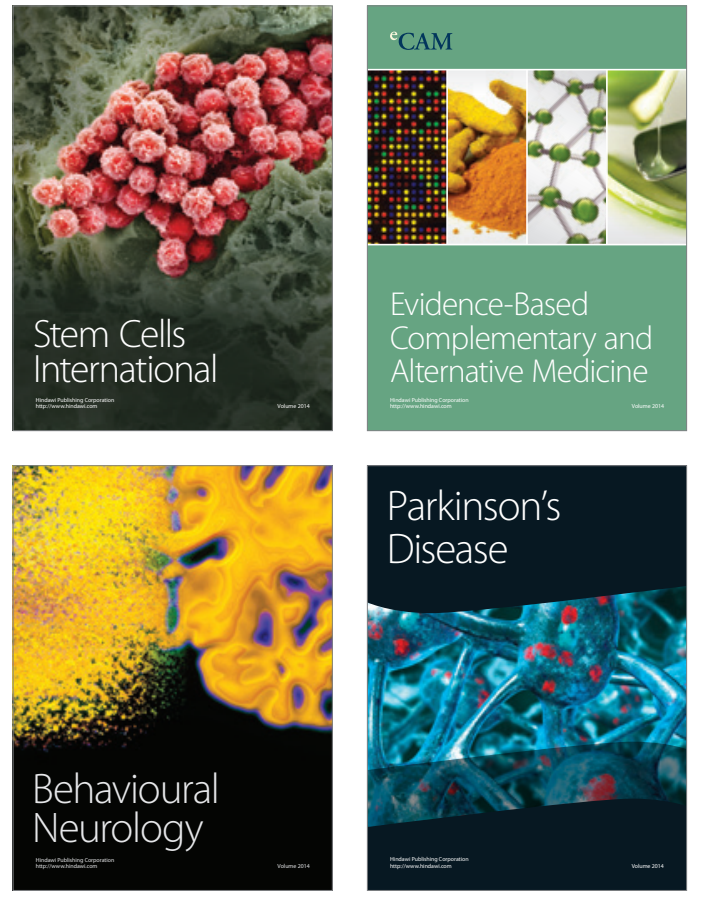
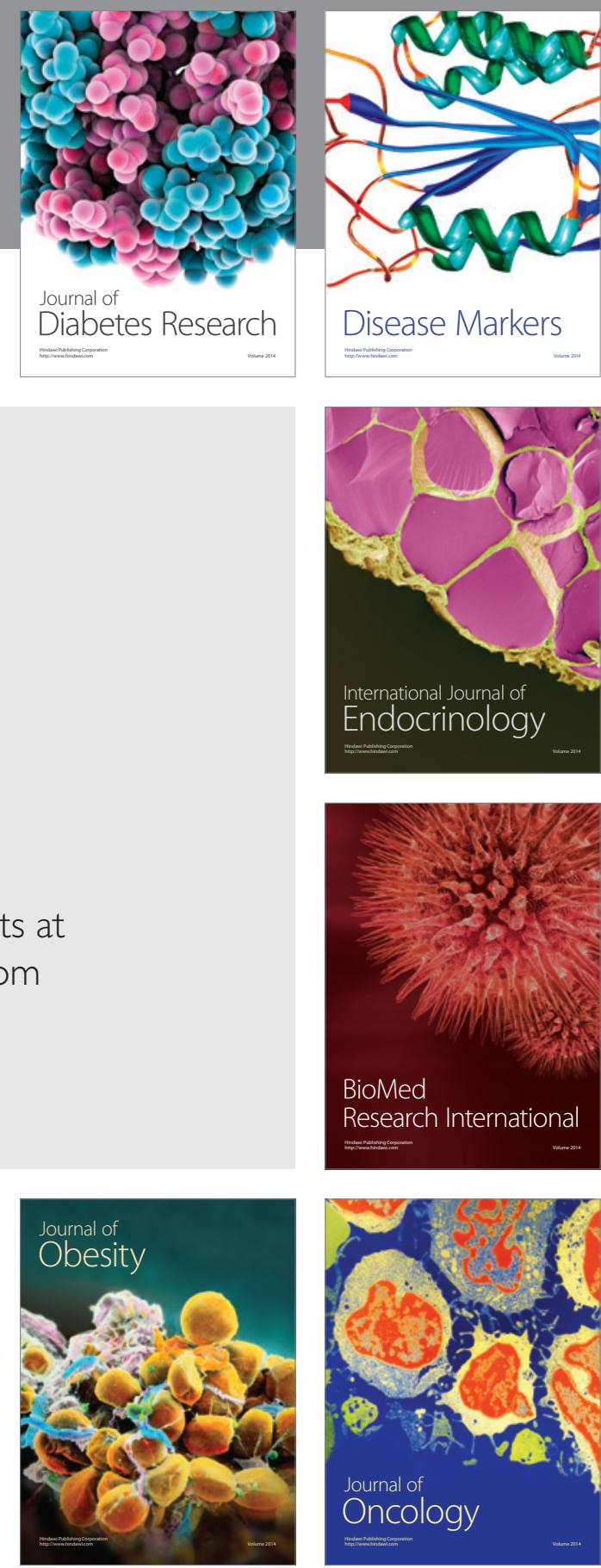

Disease Markers
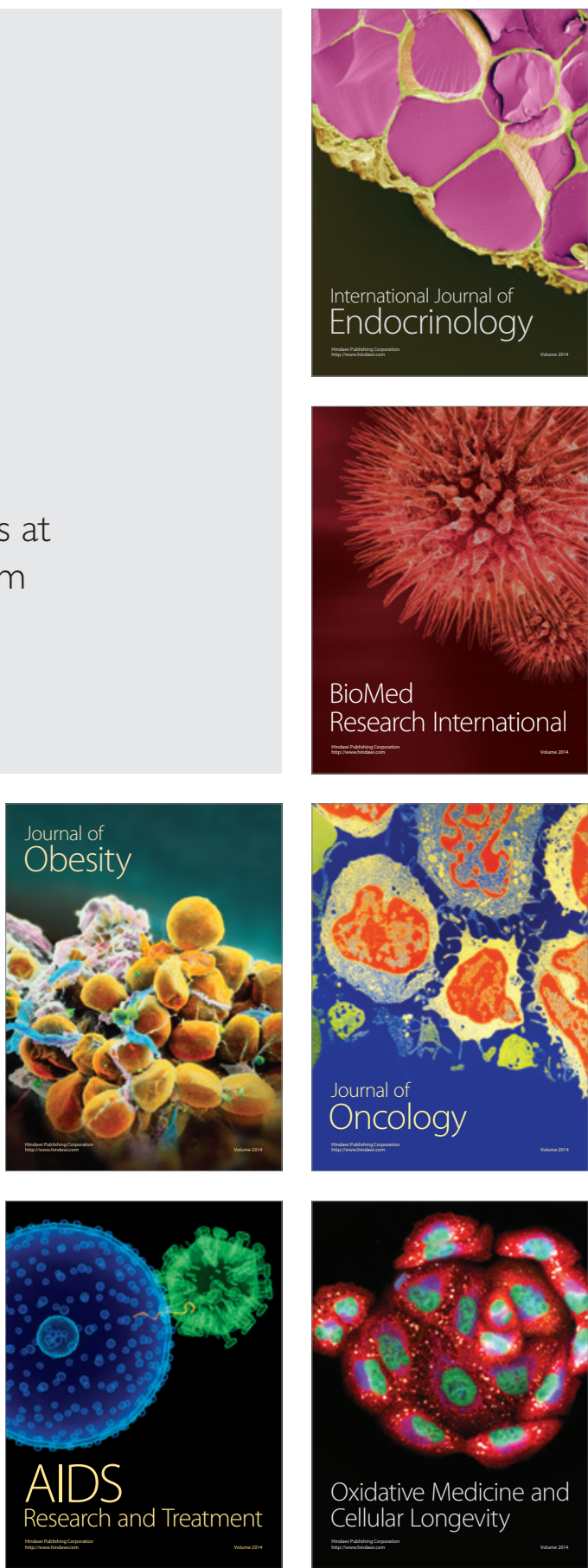